\title{
ATTITUDE OF CLINICIANS TOWARDS CLINICAL DECISION-MAKING IN PROSTHODONTICS
}

\author{
Danish Azeem Khan, Azad Ali Azad, Ayesha Aslam, Qamar Ishfaque \\ Armed Forces Institute of Dentistry/National University of Medical Sciences (NUMS) Rawalpindi Pakistan
}

\begin{abstract}
Objective: To assess the attitude of resident and consultant Prosthodontists towards clinical decision-making in complete denture prosthodontics

Study Design: A cross-sectional study.

Place and Duration of Study: Armed Forces Institute of Dentistry, Rawalpindi, from Nov 2019 to Jan 2020.

Methodology: Fifty trainee and consultant prosthodontists from all over the country were included in the study. A questionnaire consisting of 10 questions aimed at assessing the approach towards clinical decision-making in complete denture prosthodontics was circulated among the study subjects using Google Forms. Data was analyzed using SPSS version 24.

Results: Around $20(40 \%)$ prosthodontists regarded patient's personal values and preferences to be "very important" in clinical decision-making in contrast to their own values. Most of the clinicians 47 (94\%) believed their patients were quite satisfied with them and around 31 (62\%) prosthodontists believed that "choice of the best treatment results from negotiation between patients and clinicians after they have shared technical information as well as their values and preferences about the options". No significant difference was observed in choice of response between males and females or between prosthodontists with varying clinical experience for any of the questions asked $(p>0.05)$.

Conclusion: Prosthodontists participating in the present study demonstrated a positive attitude towards shared decisionmaking in complete denture prosthodontics. No differences were observed between males and females in terms of attitude towards shared decision-making practices.
\end{abstract}

Keywords: Dentists, Decision making, Prosthodontics, Shared decision making.

How to Cite This Article: Khan DA, Azad AA, Aslam A, Ishfaque Q. Attitude of Clinicians Towards Clinical Decision-Making in Prosthodontics. Pak Armed Forces Med J 2021; 71(5): 1782-1786. doi: https://doi.org/10.51253/pafmj.v71i5.3846

This is an Open Access article distributed under the terms of the Creative Commons Attribution License (https://creativecommons.org/licenses/by-nc/4.0/), which permits unrestricted use, distribution, and reproduction in any medium, provided the original work is properly cited.

\section{INTRODUCTION}

Decision-making is a complex process. In healthcare practice, it becomes compounded owing to the gravity of the situations, their prognosis and impact on human life, both in terms of duration and quality ${ }^{1}$. Ideal clinical decision-making (CDM) is an amalgam of best available scientific evidence, clinician's experience and judgement, clinical presentation of the disease and patient's preferences ${ }^{2-4}$. Such a decision-making process leads to the development of an ideal treatment plan tailored for that particular patient. However, it is considered as a "cumbersome" process 5 .

It has been observed that different clinicians may come up with different decisions for a similar case ${ }^{6}$. In terms of decision-making, literature has described five diverse models of doctor-patient relationship namely "Paternalism" where clinician 'knows best' and is dominant, making the decision for the passive patient; "Consumerism or Informative" where patient is an

Correspondence: Dr Danish Azeem Khan, Prosthodontics Department, Armed Forces Institute of Dentistry, Rawalpindi Pakistan

Received: 07 Feb 2020; revision received: 12 Mar 2020; accepted: 19 Mar 2020 autonomous role, treatment focuses on patient's wishes and preferences only; "Doctor-as-agent Model" the opposite of informative model where doctor informs the patient but makes the decision assuming that he/she knows the patient's preferences; "Family-centered Model" that incorporated the family in the decision process; and, "Shared Decision-Making" where a balance is reached between clinician's judgement and patient's preferences"7,8. With increasing awareness of both the clinicians and patients, shared decision-making is gradually replacing traditional forms of decisionmaking in all aspects of medical and dental healthcare, thereby putting the patient at the center of the complex decision-making process ${ }^{9,10}$.

It is important to evaluate the attitude of clinicians and residents towards clinical decision-making, and to highlight any deficiencies or areas on improvement. Therefore, the aim of this study was to assess the attitude of resident and consultant prosthodontists towards clinical decision-making in complete denture prosthodontics. The knowledge thus gained will help improve the standard of clinical training in the subject, 
with an increased focus on shared decision-making practices.

\section{METHODOLOGY}

A cross-sectional study was conducted at Armed Forces Institute of Dentistry, Rawalpindi. Prior approval from institute's ethics committee was sought (ERC /2019/OA-37). WHO sam-ple size calculator was used to calculate the sample size. Keeping the confidence level (1- $\alpha)$ at 95\%, absolute precision (d) at 0.9 and anticipated population proportion $(p)$ at $0.87,7$ a sample size of 50 was calculated. Non-probability consecutive sampling was done.

Inclusion Criteria: Final year FCPS xtrainees or consultant prosthodontists, both male and female, from all over the country were included in the study. Exclusion Criteria: Dentists pursuing other specialties were excluded.

A questionnaire consisting of 10 questions, adapted from the study of Barber et al , aimed at assessing the approach towards clinical decision-making in complete denture prosthodontics was circulated among the study subjects using Google Forms until the desired sample size was reached.

Data was analyzed using SPSS-24. Descriptive statistics were calculated. Fisher's exact test was appiled. The $p$-value of $\leq 0.05$ was taken as significant.

\section{RESULTS}

A total of 50 subjects participated of which 19 $(38 \%)$ were male and 31 (62\%) were female. Mean age of the study subjects was $32.26 \pm 7.2$ years (range: $24-$ 55 years). Half of the subjects $25(50 \%)$ had a clinical experience of less than 5 years, $14(28 \%)$ reported a clinical experience of 6-10 years while 11 subjects $(22 \%)$ reported a clinical experience of more than 10 years.

Figure- 1 shows the results in response to Question 1,2 and 3 of the questionnaire that aimed to identify the level of importance of clinician's personal values, "values" of patient's family \& friends and patient's own "values" in making treatment decisions. While 19 (38\%) Prosthodontists considered their own beliefs and "values" as "very important" in decisionmaking, a slightly higher number 20 (40\%) regarded patient's personal "values" and preferences to be equally "very important". In contrast, 16 (32\%) prosthodontists had a neutral response regarding the significance of beliefs of patient's family and friends.

In response to question 4 that asked "how much do your own personal "values" (beliefs, priorities, preferences) influence your presentation of material to patients who are in the process of choosing among different treatment options", $43(86 \%)$ prosthodontists considered their own "values" did affect the presentation of materials to patient. Of these, 9 subjects $(18 \%)$ responded their own "values" affected material presentation "a lot" (Figure-2).

Figure-3 depicts the level of patient satisfaction observed by prosthodontists. While majority 47 (94\%) clinicians thought their patients were satisfied with them, only 1 clinician reported their patients to be

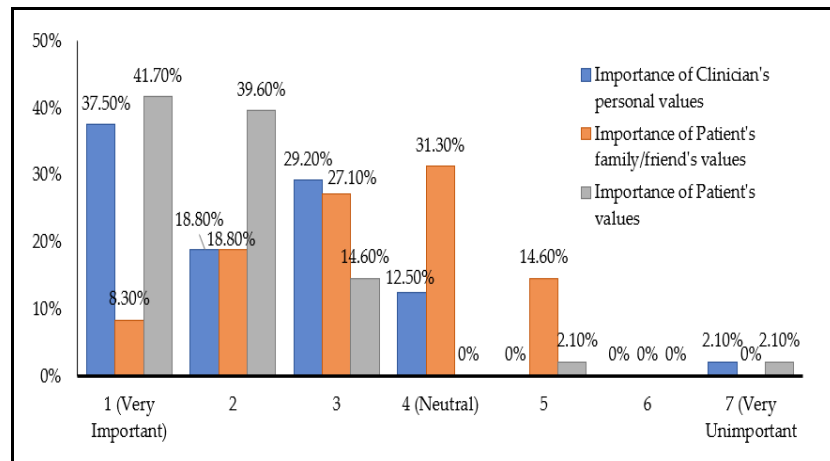

Figure-1: Level of importance given to personal values, patient's and values of patient's family and friends during clinical decision-making by study subjects (responses to questions 1, 2 \& 3).

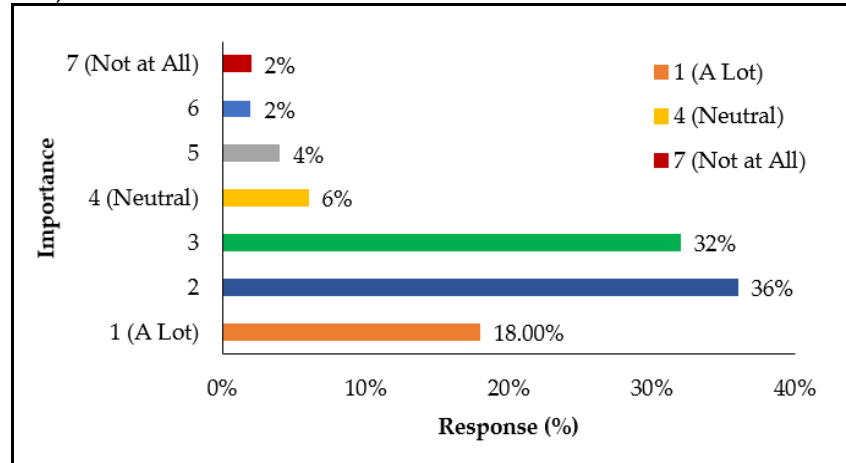

Figure-2: Response of study subjects to question 4 "How much do your own personal "values" (beliefs, priorities, preferences) influence your presentation of material to patients who are in the process of choosing among different treatment options?".

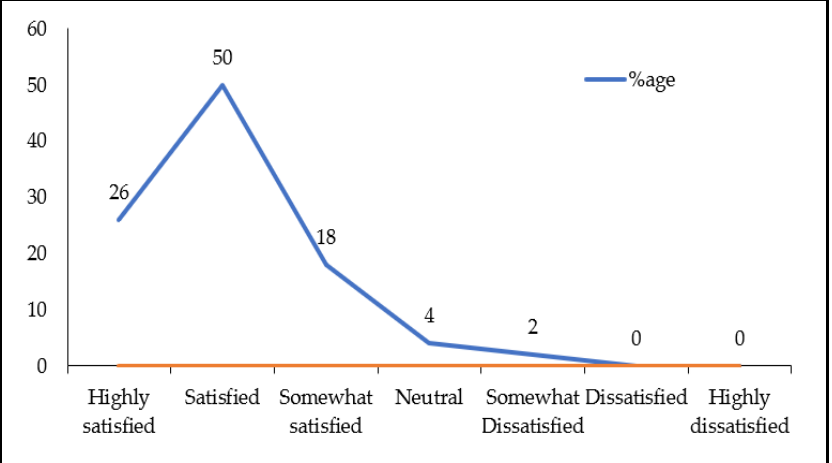

Figure-3: Level of satisfaction of patients with decision-making process as perceived by study subjects. 
somewhat dissatisfied. In response to question 6, 31 $(62 \%)$ prosthodontists believed that "choice of the best treatment results from negotiation between patients and clinicians after they have shared technical information as well as their values and preferences about the options" (Table-I). Table-II depicts the responses to the last question i.e. response of a clinician when a patient says "what would you do if you were me?" where 20 $(40 \%)$ clinicians reported offering an answer as if they were choosing for themselves. No significant difference was observed in choice of response between males and females $(p=0.871)$ or between prosthodontists with varying clinical experience $(p=0.664)$.
Decision-making in complete denture Prosthodontics is extremely challenging. Each patient presents with a unique yet chronic condition with multiple possible treatment options ${ }^{12}$. It is imperative to involve the patient in prosthodontic decision-making since each treatment option comes with its own share of functional outcomes, cost and complications ${ }^{7}$. The onus lies with the clinician in making the patients comfortable, involving them in the decision-making process and share the responsibility of the outcomes.

Ethical decision-making is one of the core competencies required from a clinician or a prospective one ${ }^{13}$. Quality of postgraduate training plays an important

Table-I: Response of study subjects to question "Ideally, how should clinicians and patients arrive at the optimal treatment option for a patient?".

\begin{tabular}{|c|c|c|c|c|}
\hline Response Choice of the Best Solution is & Overall (\%) & Male n (\%) & Female n (\%) & $p$-value \\
\hline $\begin{array}{l}\text { "Fundamentally a technical decision; the clinician should make a strong } \\
\text { recommendation to the patient and seek their endorsement." }\end{array}$ & $10 \%$ & $3(15.78 \%)$ & $2(6.45 \%)$ & \multirow{5}{*}{0.135} \\
\hline $\begin{array}{l}\text { "Partly a technical decision, and partly based on clinician's preference } \\
\text { given what he/she knows about the patient." }\end{array}$ & $14 \%$ & $1(5.26 \%)$ & $6(19.35 \%)$ & \\
\hline $\begin{array}{l}\text { "Results from negotiation between patients and clinicians after they } \\
\text { have shared technical information as well as their values and } \\
\text { preferences about the options" }\end{array}$ & $62 \%$ & $10(52.63 \%)$ & $21(67.74 \%)$ & \\
\hline $\begin{array}{l}\text { "Partly a technical decision and partly based on the patient's informed } \\
\text { preferences, regardless of the clinician's preferences" }\end{array}$ & $12 \%$ & $4(21.05 \%)$ & $2(6.45 \%)$ & \\
\hline $\begin{array}{l}\text { "Entirely based on patient preferences; the clinician should only make } \\
\text { sure the patient has adequate information about each option" }\end{array}$ & $2 \%$ & $1(5.26 \%)$ & - & \\
\hline
\end{tabular}

Table-II: Response of study subjects to question, "Which of the following best describes your response to a patient who asks, what would you do if you were me?".

\begin{tabular}{|c|c|c|c|c|}
\hline Response & Total (\%) & Male n (\%) & Female n (\%) & $p$-value \\
\hline $\begin{array}{l}\text { "Inform the patient that my clinical concerns and preferences are likely } \\
\text { different from theirs, and decline to offer an answer" }\end{array}$ & $12 \%$ & $2(10.52 \%)$ & $4(12.90 \%)$ & \multirow{5}{*}{0.871} \\
\hline $\begin{array}{l}\text { "Share my own clinical concerns and preferences to clarify differences } \\
\text { with patient's circumstances, and offer an answer as if I were choosing } \\
\text { for myself" }\end{array}$ & $48 \%$ & 8 (42.11\%) & $16(51.61 \%)$ & \\
\hline $\begin{array}{l}\text { "Answer as if I was the patient, and use my own values/preferences to } \\
\text { choose among the different treatment options" }\end{array}$ & $20 \%$ & $5(26.32 \%)$ & $5(16.13 \%)$ & \\
\hline $\begin{array}{l}\text { "Answer as if I was the patient, and use my interpretation of this } \\
\text { patient's values/preferences to choose among the different treatment } \\
\text { options" }\end{array}$ & $18 \%$ & $4(21.05 \%)$ & $5(16.13 \%)$ & \\
\hline $\begin{array}{l}\text { "Answer as if I was the patient, and use my interpretation of an average } \\
\text { patient's values/preferences to choose among the different treatment } \\
\text { options" }\end{array}$ & $2 \%$ & - & $1(3.23 \%)$ & \\
\hline
\end{tabular}

\section{DISCUSSION}

Effective decision-making is one of the mandatory competencies described in any postgraduate dental curriculum. The present study aimed to assess the attitude of trainee and consultant prosthodontists towards clinical decision-making for completely edentulous patients using a closed-ended questionnaire that had been previously tested and published. In fact, a legislation in US has declared shared decision-making mandatory and to be considered as the highest form of "informed consent"11. role in polishing the decision-making skills of doctors 14. The results of the present study revealed that prosthodontists considered the patient's values of more importance in relation to decision-making in comparison to their own values or those of patient's friends or family. This signifies an inclination towards shared decision-making, allowing the patient to collaborate and give his/her input. This finding was endorsed by Barber et al ${ }^{7}$, who reported a similar attitude among prosthodontists in UK who preferred patient's values over their own. Also, literature shows that shared 
decision-making is the preferred approach in all dental care settings ${ }^{15}$. Shared decision-making has been reported to not only improve patient health and treatment outcomes, but also helps in reducing treatment cost, increasing patient satisfaction and adherence to treatment as well as in translating evidence-based research into clinical practice ${ }^{16,17}$.

Regarding how clinicians present material to the patients, responses of this study indicate that clinicians tend to assume a paternalistic role. This shows that although the study subjects are in favor of shared decision-making, the said approach is not being practiced in its entirety. Similar results were reported by Koka et $a l^{18}$, who found that North American prosthodontists' values affected the presentation and choice of treatment options. Omar et al ${ }^{19}$, also found that prosthodontists generally chose their preferred 'more possible' treatment options, and asked specific questions from patients that would facilitate the recommendation of their preferred treatment.

The last question that focused on "what would you do if you were me?" received a variety of responses. Studies argue that "declining to offer the patient an answer is perhaps the most professional and ethics approach" in such a case ${ }^{7}$. This is because what the patient is actually in search of is a recommendation by the prosthodontist regarding which treatment option to choose, hence not fulfilling his/her own responsibility in the decision-making process. However, this option of declining was not popular among the study subjects where only $6(12 \%)$ clinicians favored its choice. Around 24 (48\%) prosthodontists responded that they would share their concerns and answer as if choosing for themselves, while $9(18 \%)$ said they would use their interpretation of the patient's values to choose a treatment option. This implies a "doctor-as-agent' approach to decision-making. It is, however, debatable that how accurately a clinician can comprehend a patient's values, beliefs and preferences during a consultation appointment in order to serve as a 'surrogate' decision-maker. Medical literature shows that surrogate decision-makers fail to accurately predict patient preferences, and are biased by their own wishes and choices ${ }^{20,21}$. Doctors, when choosing for their patients, tend to make conservative choices probably due to fear of litigation or due to fear of treatment failure ${ }^{7,22}$. This one question actually embodies reality. Prosthodontists often face such questions in real-life situations, and their response to this question may represent their personal experience.
No gender-based differences were observed in terms of attitude towards decision-making in complete denture prosthodontics. Although females have been reported to show more empathy to their patients, improving communication and enhancing patient participation in decision-making process in comparison to male doctors ${ }^{23}$, this study find any such differences. This may be attributed to the uniform standard of postgraduate training or perhaps to reporting bias inherent in survey-based studies.

Decision-making role preferred by patients is dynamic-it will vary from one patient to another. It may also vary within an individual from time to time. A number of factors affect this choice of preferred role including age, gender and mental state of the patient ${ }^{17}$, clinical setting e.g. hospital vs private practice ${ }^{15}$, knowledge about the problem and level of trust in the treating clinician ${ }^{24}$, available time and previous healthrelated experience ${ }^{8}$. For a dentist to deal with such changing preferences, he/she needs to adapt to the varying clinical situations. The dentist may aid the patient in arriving at a decision, but in no way should the autonomy of the patient be violated.

The strengths of our study include the use of a data collection tool that had already been tested in a previous study 7 . The identity of the respondents was kept anonymous. Prosthodontists from all over the country were targeted. However, survey-based studies are never free from bias, which is an inherent weakness of this study as well. In addition, the sample size may appear small. It must, however, be mentioned that prosthodontists make up a very small percentage of the total registered dental surgeons in the country which are not $>25000$ at the moment ${ }^{25}$. Hence, a small sampling frame does represent the prosthodontic fraternity.

The overall attitude of prosthodontists towards shared decision-making observed in our study is positive. Slight contradictions between attitude and practice as highlighted by the responses of study subjects need to be evaluted forther. Emphasis should be laid on promoting shared decision-making practice and respecting patient autonomy during postgraduate training as well as clinical practice in Prosthodontics. Postgraduate curriculum should address assessment of learning objectives in the affective domain, especially communication skills and decision-making process. Post-graduate training standards throughout the country should be uniform as differences in training 
can significantly affect clinical decisions and decisionmaking practice ${ }^{14}$.

\section{CONCLUSION}

Prosthodontists participating in this study demonstrated a positive attitude towards shared decision-making in complete denture prosthodontics. No differences were observed between males and females in terms of attitude towards shared decision-making practices. More emphasis is required during postgraduate training to translate this positive attitude into clinical practice.

\section{Conflict of Interest: None.}

\section{Authors' Contribution}

DAK: Data collection, study design.

AAK: Supervision and critical review.

AA: Data writing and analysis.

QI: Manuscript writing.

\section{REFERENCES}

1. Alani A, Bishop K, Djemal S. The influence of specialty training, experience, discussion and reflection on decision making in modern restorative treatment planning. Br Dent J 2011; 210(4): E41E49.

2. Elangovan S, Guzman-Armstrong S, Marshall TA, Johnsen DC. Clinical decision making in the era of evidence-based dentistry. J Am Dent Assoc 2018; 149(9): 745-747.

3. Tolentino PHMP, Rodrigues LG, deTorres ÉM, Franco A, Silva RF. Tooth extractions in patients with periodontal diseases and clinical decision-making process. Acta Stomatol Croat 2019; 53(2): 141-149.

4. Alaseeri R, Rajab A, Banakhar M. factors influencing nurses' decision-making process: an integrative literature review. IOSR J Nurs Health Sci 2019; 8(4): 36-48.

5. Shifaza F, Hamiduzzaman M. System factors influencing the australian nurses' evidence-based clinical decision making: a systematic review of recent studies. Evid Based Healthc 2019; 9(2): 17-30.

6. O'Sullivan E, Schofield S. Cognitive bias in clinical medicine. J R Coll Physicians Edinb 2018; 48(1): 225-232.

7. Barber A, Puryer J, Leary S, McNally L, O'Sullivan D. Attitudes towards prosthodontic clinical decision-making for edentulous patients among south west deanery dental foundation year one dentists. . Dent J 2016; 4(2): 12-26.

8. Tariman JD, Berry DL, Cochrane B, Doorenbos A, Schepp K. Physician, patient and contextual factors affecting treatment decisions in older adults with cancer: A literature review. Oncol Nurs Forum 2012; 39(1): E70-E83.
9. Frosch DL, May SG, Rendle KA. Authoritarian physicians and patients' fear of being labeled 'difficult'among key obstacles to shared decision making. Health Aff 2012; 31(5): 1030-1038.

10. Krist A, Tong S, Aycock R, Longo D. Engaging patients in decision-making and behavior change to promote prevention. Info Serv Use 2017; 32(2): 105-122.

11. Molinari M, Guler S, Hurton S. Levels in decision making and techniques for clinicians. Int J Dig Dis 2015; 1(2): 1-11.

12. Deshpande S, Lambade D, Chahande J. Development and evaluation of learning module on clinical decision-making in Prosthodontics. J Indian Prosthodont Soc 2015; 15(2): 158-161.

13. Durand M-A DP, Song J, Yen RW, Barr PJ. Shared decision making embedded in the undergraduate medical curriculum: A scoping review. PloS One 2018; 13(11): e0207012-e0207016.

14. Pineda K, Bueno R, Alvarado C, Abella F, Roig M, DuranSindreu F. Influence of academic training in endodontics and implantology on decision-making in undergraduate students. Aust Endod J 2018; 44(1): 40-45.

15. Moeen F, Khan YH, Hasan U. A study to evaluate patient preferences in the decision making of dental treatment. J Islamic Int Med Coll 2012; 7(1): 3-7.

16. Légaré F, Witteman HO. Shared decision making: examining key elements and barriers to adoption into routine clinical practice. Health Aff 2013; 32(2): 276-284.

17. Ghane A, Huynh HP, Andrews SE, Legg AM, Tabuenca A, Sweeny K. The relative importance of patients' decisional control preferences and experiences. Psy Health 2014; 29(10): 1105-1118.

18. Koka S, Eckert SE, Choi YG, Montori VM. Clinical decisionmaking practices among a subset of North American prosthodontists. Int J Prosthodont 2007; 20(6): 606-608.

19. Omar R, Akeel R. Prosthodontic decision-making: what unprompted information do dentists seek before prescribing treatment?. J Oral Rehabil 2010; 37(2): 69-77.

20. Marks MAZ, Arkes HR. Patient and surrogate disagreement in end-of-life decisions: can surrogates accurately predict patients' preferences?. Med Decis Making 2008; 28(4): 524-531.

21. Garcia-Retamero R, Galesic M. Doc, what would you do if you were me? On self-other discrepancies in medical decision making. J Exp Psychol 2012; 18(1): 38-51.

22. Garcia-Retamero R, Galesic M. On defensive decision making: how doctors make decisions for their patients. Health Expect 2014; 17(5): 664-669.

23. McKay JC. The feminization of dentistry: imp-lications for the profession. J Can Dent Assoc 2012; 78(1): c1-c7.

24. Frosch DL, May SG, Rendle KA. Authoritarian physicians and patients' fear of being labeled 'difficult'among key obstacles to shared decision making. Health Aff 2012; 31(5): 1030-1038.

25. PMDC. Pakistan Medical \& Dental Council Islamabad, Pakistan: PMDC; 2019, [Internet] Available from: www.pmdc.gov.pk. [Accessed on Dec 22, 2019]. 